\title{
Anti-proliferation and Insulin Resistance Alleviation of Hepatocellular Carcinoma Cells HepG2 in Vitro by Chinese Propolis
}

\author{
Yazhou Zhao, Wenli Tian, Wenjun Peng* \\ Institute of Apiculture, Chinese Academy of Agricultural Sciences, Beijing, China \\ *Corresponding author: pengwenjun@vip.sina.com
}

Received March 09, 2014; Revised May 04, 2014; Accepted May 20, 2014

\begin{abstract}
Previous studies suggest affirmative effects of propolis on cancers and diabetes, due to its abundant flavonids. But information is rarely available with regard to its effects on hepatocellular carcinoma cells (HCC), particularly on cell proliferation and insulin resistance (IR). We measured the flavonids of ethanol extract from Chinese propolis (EEP) by HPLC. IR model of HepG2 cells were established, which were treated with different kinds and doses of propolis. The anti-proliferation and IR alleviation of HepG2 cells were studied. As result, EEP contained many flavonoids. Compared with other two solvents (PEG and DMSO), olive oil (dosage: $200 \mu \mathrm{g} / \mathrm{mL}$ ) could significantly inhibit cell proliferation and alleviate IR of HepG2 cells. EEP dissolved in DMSO (mass ratio: 2:1; dosage: $300 \mu \mathrm{g} / \mathrm{mL}$ ) exhibited anti-proliferative effect on HepG2 cells. When EEP was dissolved in olive oil (mass ratio: 2:1; dosage: $300 \mu \mathrm{g} / \mathrm{mL}$ ), IR of HepG2 cells was greatly alleviated. As a conclusion, olive oil may be more suitable as auxiliary solvent of propolis as to improve its biological activities. High-dose propolis could effectively inhibit the proliferation and alleviate the IR of HepG2 cells in vitro.
\end{abstract}

Keywords: cell proliferation, flavonoids, HepG2 cells, insulin resistance, propolis

Cite This Article: Yazhou Zhao, Wenli Tian, and Wenjun Peng, "Hepatocellular Carcinoma Cells HepG2 in Vitro by Chinese Propolis.” Journal of Food and Nutrition Research, vol. 2, no. 5 (2014): 228-235. doi: 10.12691/jfnr-2-5-4.

\section{Introduction}

Hepatocellular carcinoma (HCC) is one of the most common therioma, ranking third only to gastric cancer and esophageal cancer. In addition, it is very hard to diagnose in the early phase of symptom development due to lack of awareness, leading to the seriously affected life quality of patients [1]. HCC is mainly characterized by abnormal cycles and limitless proliferation of tumor cells. Therefore, its most widely accepted therapy is the interference with cell cycles, including the inhibiting the proliferation and growth of tumor cells, or inducing the apoptosis of tumor cells [2]. Bortezomib has been found to inhibit the cell proliferation in two different HCC cell lines, making it attractive for future experimentation in animal models [3]. Vasoative intestinal peptide can also inhibit the proliferation of HepG2 cells in vitro, and its antiproliferative effects may offer a novel and promising approach of suppressing HCC [4]. Insulin resistance (IR) is a state in which a given concentration of insulin produces a less-than-expected biological effect. The liver and its peripheral tissues are target organizations and main lesion tissues of IR [5]. Moreover, IR is mainly characterized by reduced glucose consumption of target cells with a normal insulin level [6]. The situation of IR can be successfully mitigated by improving the insulin digestion. Eriodictyol and 7-O-methylaromadendrin, which are both flavonoids, have been found to increase glucose uptake and alleviate IR, suggesting anti-diabetic properties of flavonoids $[7,8]$. Flavonoids are the main components in Chinese propolis, and some researchers have reported the anti-diabetic effects of propolis from different geographic regions [9,10]. Based on these reports, studies on anti-proliferation and IR alleviation of human HCC cells have important theoretical and practical significance.

Propolis is a mixture of various amounts of beeswax and resins collected by honeybees from secretions of plants, particularly from branches, buds or callus. These secretions are interfused with other secretions from maxillary and wax glands of honeybee. Finally, an aromatic solid gelatinous substance is successfully processed, which is called as propolis [11,12]. According to historical records, propolis has been always applied in drugs since centuries ago. Egyptians pioneered the use of propolis to retard carcass decay [13]. In Greece and Ancient Roma, doctors used propolis as antiseptic, disinfectant and cicatrizant for wound treatment. Ancient Europeans paid more attentions to the anti-bacterial properties of propolis [14,15]. Propolis possesses many biological activities due to its abundant flavonoids, such as broad-spectrum bactericidal, antioxidant, immune regulation, anti-inflammation and anti-cancer [14]. Especially, propolis has some affirmative effects on 
different cancers, such as laryngeal carcinoma, renal adenocarcinoma and prostate cancer $[16,17]$. Despite the broad anti-cancer potential of propolis, information is rarely available with regard to its effects on HCC cells, particularly on cell proliferation and IR. In the current investigation, we established an IR model of HepG2 cells using supra-physiological concentrations of insulin and glucose solutions. Furthermore, the capacity of antiproliferation and IR alleviation by propolis was also assessed in liver cancer cells in vitro.

\section{Materials and Methods}

\subsection{Instruments and Reagents}

Thermostatic oscillator (THZ-C) was purchased from Aiwa Optoelectronic Technology Co., Ltd. (Wuxi, China). Ultraviolet visible spectrophotometer (752N) was provided by Hanker International Group Co., Ltd. (China). Centrifuge (5804R) was obtained from Eppendorf Co., Ltd. (China). SANYO carbon dioxide incubator (MIR-253) was supplied by Biotechnology Co., Ltd. (Shanghai, China).

The standards used in HPLC analysis, tryosin and fetal bovine serum (FBS) were purchased from Sigma-Aldrich (St. Louis, USA). Thiazolyl blue tetrazolium bromide (MTT), glucose and insulin were obtained from Beijing Chemical Reagent Company. Human hepatoma HepG2 cell lines were kept in our laboratory. Dulbecco's modified eagle medium (DMEM) was purchased from Takara Biotechnology Co., Ltd. (Dalian, China). Glucose reagent kit was produced by Randox Laboratories Ltd. (the United Kingdom).

\subsection{Preparation of Ethanol Extract from Propolis (EEP)}

Raw propolis was collected from honeybee hive (Apis mellifera L.) in Linyi $\left(35.24^{\circ} \mathrm{N}, 118.53^{\circ} \mathrm{E}\right)$ locating in
North China in April, 2012, and it mainly origins from poplar (Populus sp.). Raw propolis was ground into fine powder, mixed with 95\% (v/v) ethanol (solid-liquid ratio was $1: 10$ ) in a beaker flask and incubated at a constant temperature $\left(40^{\circ} \mathrm{C}\right)$ in a water bath for $24 \mathrm{~h}$. During the period of incubation, the beaker flask was gently wobbled every 2 h. Subsequently, the supernatant was obtained through the filtration on Whatman No. 4 filter paper. The collected supernatant was evaporated in a rotary evaporator under a reduced pressure at $55^{\circ} \mathrm{C}$. The extract was dried in an oven until it reached an invariable weight. The final extract was stored at $-20^{\circ} \mathrm{C}$ prior to further analysis.

\subsection{Measurement of Flavonoid Content with HPLC}

Chromatographic analyses of flavonoid content were carried out using the method of Chinese Standard (GB/T 19427-2003) and operated on an Agilent HPLC system, which was equipped with a vacuum degasser G1322A, a quaternary pump G1311A, an autosampler G1329A, a programmable variable wavelength detector G1314B and a thermostatted column compartment G1316A. Flavonoid separation was performed on Sepax GP-C18 column (4.6 $\mathrm{mm} \times 150 \mathrm{~mm}, 3 \mu \mathrm{m})$ at a detection wavelength of 270 $\mathrm{nm}$ at $28^{\circ} \mathrm{C}$. The mobile phases consisted of methanol and water at a ratio of $58 / 42(\mathrm{v} / \mathrm{v})$, and the $\mathrm{pH}$ of the mobile phase was adjusted to 3 with phosphoric acid at a flow rate of $0.7 \mathrm{~mL} / \mathrm{min}$. All sample solutions were filtered through $0.22-\mu \mathrm{m}$ membrane filters, and the injection volume was $10 \mu \mathrm{L}$.

\subsection{Setting of Drug Treatment Groups}

The drug treatment groups were divided into propolis groups (sample groups) and non-propolis groups (solvent groups, including polyethylene glycol, PEG; dimethyl sulfoxide, DMSO; olive oil). Table 1 lists detailed information.

Table 1. The setting of the drug treated groups

\begin{tabular}{|c|c|c|c|}
\hline Drug treated groups & Drug treated sub-groups & Material (mass ratio) & Dosage $(\mu \mathrm{g} / \mathrm{mL})$ \\
\hline \multirow{2}{*}{ PL } & PLP & PEG & 20 \\
\hline & PLs & PEG + propolis (2:1) & 30 \\
\hline \multirow{2}{*}{ PM } & PMp & PEG & 100 \\
\hline & PMs & PEG + propolis (2:1) & 150 \\
\hline \multirow{2}{*}{$\mathrm{PH}$} & PHp & PEG & 200 \\
\hline & PHs & PEG + propolis (2:1) & 300 \\
\hline \multirow{2}{*}{ DL } & DLp & DMSO & 20 \\
\hline & DLs & DMSO + propolis (2:1) & 30 \\
\hline \multirow{2}{*}{$\mathrm{DM}$} & DMp & DMSO & 100 \\
\hline & DMs & DMSO + propolis (2:1) & 150 \\
\hline \multirow{2}{*}{$\mathrm{DH}$} & DHp & DMSO & 200 \\
\hline & DHs & DMSO + propolis (2:1) & 300 \\
\hline \multirow{2}{*}{ OL } & OLp & Olive oil & 20 \\
\hline & OLs & Olive oil + propolis (2:1) & 30 \\
\hline \multirow{2}{*}{$\mathrm{OM}$} & OMp & Olive oil & 100 \\
\hline & OMs & Olive oil + propolis (2:1) & 150 \\
\hline \multirow{2}{*}{$\mathrm{OH}$} & ОНр & Olive oil & 200 \\
\hline & $\mathrm{OHs}$ & Olive oil + propolis (2:1) & 300 \\
\hline
\end{tabular}




\subsection{Cytological Experiments}

\subsubsection{Cell Recovery}

Frozen HepG2 cells were thawed in a $37^{\circ} \mathrm{C}$ water bath for $2 \mathrm{~min}$ and resuspended at $40^{\circ} \mathrm{C}$ on shaker at $60 \mathrm{rpm}$. Subsequently, the cell suspension was centrifuged at 800 rpm for 5 min.

\subsubsection{Cell Culture}

The supernatant was removed, and cell pellet was resuspended in $10 \mathrm{~mL}$ DMEM containing $10 \%$ FBS and $1 \%$ penicillin-strptomycin. Cells were then cultured at a saturated humidity of $5 \% \mathrm{CO}_{2}$ and $37^{\circ} \mathrm{C}$ for $24 \mathrm{~h}$.

\subsubsection{Cell Digestion}

Culture medium was removed, HepG2 cells were trypsinized with $0.25 \%$ trypsin, and then the reaction was terminated by adding $10 \mathrm{~mL}$ DMEM containing 10\% FBS.

\subsubsection{Cell Vaccination}

Briefly, cells were seeded into 96-well culture plates at a density of $3 \times 10^{4}$ cells $/ \mathrm{mL}$, and $200 \mu \mathrm{L}$ of cell suspension was added into each well. The plates were incubated at a saturated humidity of $5 \% \mathrm{CO}_{2}$ and $37^{\circ} \mathrm{C}$ for $24 \mathrm{~h}$. Six wells without the drug treatment were used as CK (control check) groups.

\subsubsection{IR Model}

After $24 \mathrm{~h}$, culture medium was replaced with $100 \mu \mathrm{L}$ of DMEM containing $10^{-6} \mathrm{M}$ insulin, $1 \%$ FBS and $25 \mathrm{mM}$ glucose. Cells were cultured at $37^{\circ} \mathrm{C}$ with a $5 \% \mathrm{CO}_{2}$ saturation humidity for another $36 \mathrm{~h}$, and the culture medium was refreshed every $18 \mathrm{~h}$. Six wells without the drug treatment were separated as MG (model group) groups.

\subsubsection{Drug Treatment}

Drug treatment was carried out according to Table 1. Each drug treatment group included six wells, and treated cells were cultured at $37^{\circ} \mathrm{C}$ with a $5 \% \mathrm{CO}_{2}$ saturation humidity for $24 \mathrm{~h}$.

\subsubsection{Measurement of Relative Cell Proliferation}

Briefly, $20 \mu \mathrm{L}$ of MTT solution $(5 \mathrm{mg} / \mathrm{mL}$, dissolved in phosphate-buffered saline, PBS) was added into each well, and the culture plates were incubated at $37^{\circ} \mathrm{C}$ with a $5 \%$ $\mathrm{CO}_{2}$ saturation humidity for $4 \mathrm{~h}$ until purple precipitate was clearly visible. The supernatant was then discarded, $150 \mu \mathrm{L}$ DMSO was added into each well, and the plates were shaken at medium speed for $5 \mathrm{~min}$. The cell proliferation rate was determined according to the absorbance at a wavelength of $570 \mathrm{~nm}$ using the microplate reader. The relative cell proliferation rate of MG groups was defined as $100 \%$, whereas it of other groups was determined accordingly.

\subsubsection{Measurement of Relative Glucose Consumption Capability}

The supernatant was removed, and the wells were washed twice with PBS. Subsequently, $10 \mathrm{~mL}$ DMEM containing $10^{-6} \mathrm{M}$ insulin and $25 \mathrm{mM}$ glucose was added into each well. The plates were incubated at $37^{\circ} \mathrm{C}$ with a $5 \% \mathrm{CO}_{2}$ saturation humidity for $24 \mathrm{~h}$. The change of glucose content in the supernatant, which corresponded to the glucose consumption capacity, was determined by the glucose kit. The relative glucose consumption capacity of MG groups was defined as 1 , whereas it of other groups was determined accordingly.

\subsection{Statistical Analysis}

Data were processed by SPSS statistical software version 18.0 (SPSS, Inc., Chicago, IL, USA). Analysis of variance was performed using one-way ANOVA method, and differences within treated groups were assessed using paired $t$-tests. A $P$ value of $<0.05$ was considered statistically significant, and a $P$ value of $<0.01$ was considered statistically extremely significant. Bivariate correlation method was used to conduct correlation analysis. All of the figures were constructed using Microsoft Excel.

\section{Results}

\subsection{Flavonoid Content of EEP}

Figure 1 shows that the chromatographic profiles of EEP and flavonoid standards were recorded at $270 \mathrm{~nm}$, and their levels were shown in Table 2. The total flavonoid content of EEP was $167.00 \pm 7.00 \mathrm{mg} / \mathrm{g}$. Eight most representative flavonoids of EEP were also analyzed, including rutin, myricetin, quercetin, kaempferol, apigenin, pinocembrin, chrysin and galangin. The HPLC revealed that seven flavonoids (except for myricetin) were detected in EEP.

Table 2. Concentrations of flavonoids presented in EEP

\begin{tabular}{|c|c|c|c|}
\hline No. & Components & Acquisition time (min) & $\mathrm{mg} / \mathrm{g}$ of $\mathrm{EEP}^{\mathrm{a}}$ \\
\hline 1 & Rutin & 26.993 & $0.32 \pm 0.01$ \\
\hline 2 & Myricetin & 28.795 & 0.00 \\
\hline 3 & Quercetin & 36.357 & $12.09 \pm 0.51$ \\
\hline 4 & Kaempferol & 44.012 & $13.88 \pm 0.58$ \\
\hline 5 & Apigenin & 46.234 & $14.02 \pm 0.59$ \\
\hline 6 & Galangin & 46.247 & $44.01 \pm 1.84$ \\
\hline 7 & Pinocembrine & 48.031 & $34.94 \pm 1.46$ \\
\hline 8 & Chrysin & 48.584 & $47.73 \pm 2.00$ \\
\hline
\end{tabular}

${ }^{\mathrm{a}}$ Reported values are the means \pm SD $(n=3)$. 


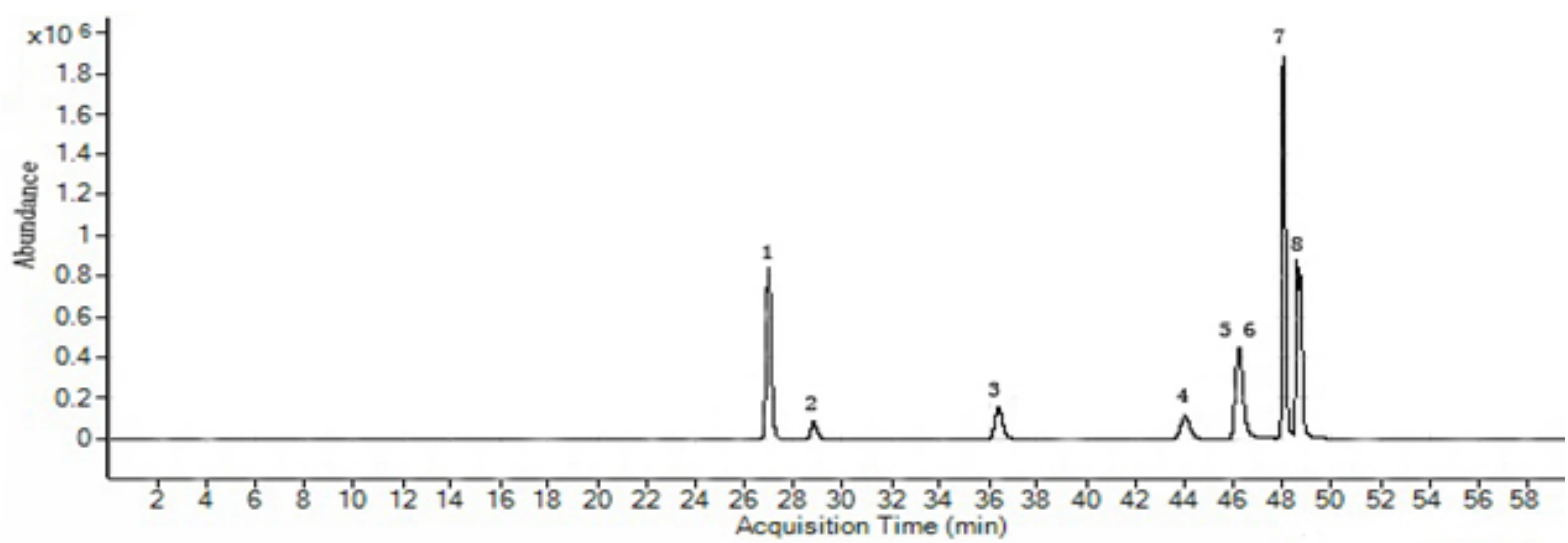

(a)

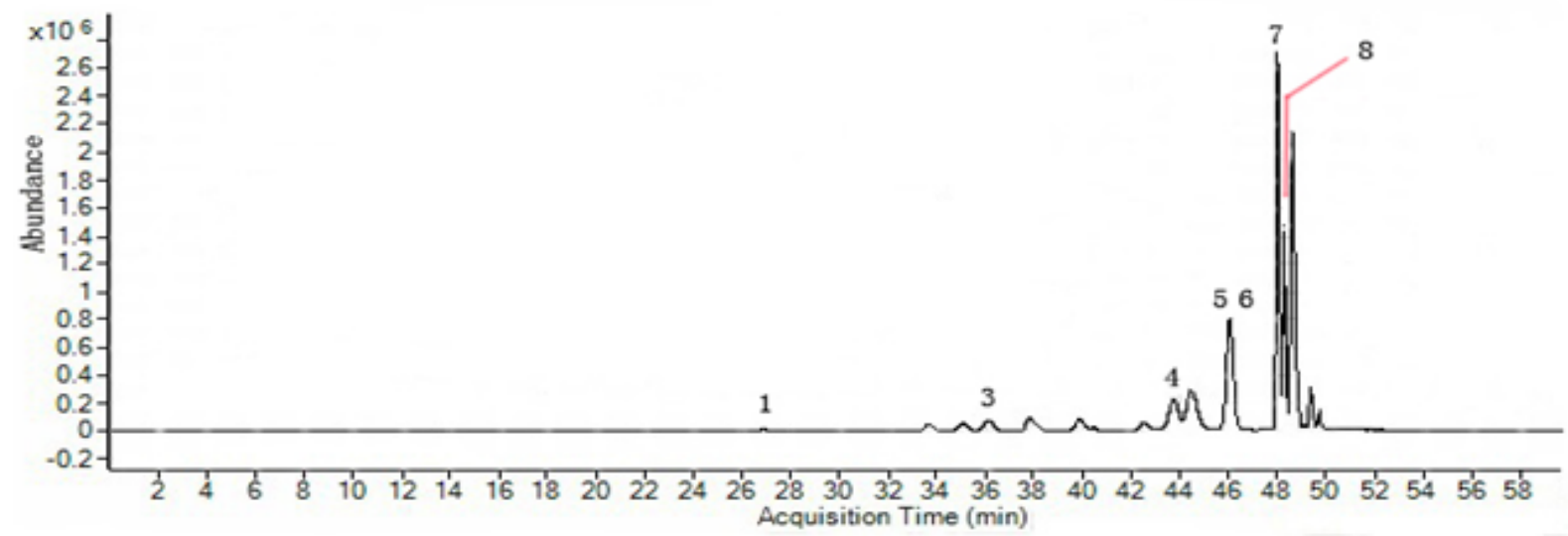

(b)

Figure 1. HPLC chromatogram of flavonoids standards (a) and EEP (b). Peaks: 1 rutin; 2 myricetin; 4 quercetin; 5 apigenin; 6 pinocembrin; 7 chrysin; 8 galangin

\subsection{Influence of Propolis on Proliferation of HepG2 Cells}

Figure 2 shows that the relative cell proliferation rate of OMp and OHp groups was $84.67 \% \pm 10.50 \%$ and $73.60 \%$ $\pm 10.38 \%$ respectively, reflecting a greater antiproliferative effect compared with other solvent groups. In addition, the proliferation of HepG2 cells was significantly inhibited in all sample groups, and the antiproliferative effect was in a concentration-dependent manner. The minimum relative cell proliferation rate was $79.29 \% \pm 5.03 \%, 49.30 \% \pm 6.45 \%$ and $19.14 \% \pm 3.39$ when the propolis concentration was $10 \mu \mathrm{g} / \mathrm{mL}, 50 \mu \mathrm{g} / \mathrm{mL}$ and $100 \mu \mathrm{g} / \mathrm{mL}$, respectively. Table 3 shows the $P$ values between different groups. In solvent groups, the relative cell proliferation rate of only OHs group was significantly different from that of CK or MG groups, with a $P$ value of 0.031 or 0.010 , respectively. Except for the OLs group, extremely significant differences in terms of the relative cell proliferation rates of all other sample groups were observed compared with CK or MG groups. Moreover, the relative cell proliferation rate of sample groups at the middle $(150 \mu \mathrm{g} / \mathrm{mL})$ and high $(300 \mu \mathrm{g} / \mathrm{mL})$ concentrations was also compared with all solvent groups, and the differences all reached an extremely significant level $(P<$ 0.01). The pairwise comparisons showed that the relative cell proliferation rate was in a concentration-dependent manner. Namely, a greater anti-proliferative effect was observed once the propolis concentration was increased.

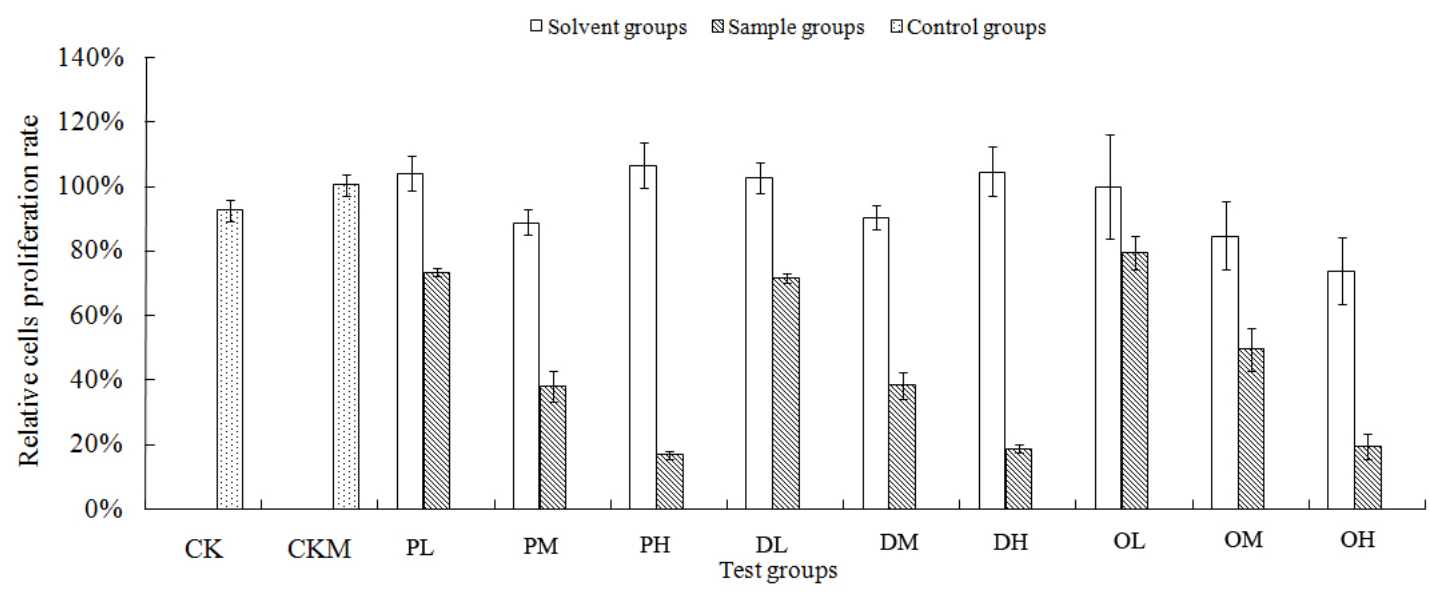

Figure 2. Relative cells proliferation rate of HepG2 cells of treated groups 
3.3. Influence of Propolis on IR of HepG2 Cells

Figure 3 shows the relative glucose consumption capacity of all groups. In all solvents groups, OMp and $\mathrm{OHp}$ groups exhibited some relieving effects on IR of HepG2 cells, with a relative glucose consumption capacity of $1.31 \pm 0.12$ and $1.47 \pm 0.18$, respectively. In all sample groups, the IR of HepG2 cells was significantly reduced when the propolis concentration was increased. Particularly, the relative glucose consumption capacity of OMs and OHs groups was $1.73 \pm 0.14$ and $4.11 \pm 0.58$, respectively.

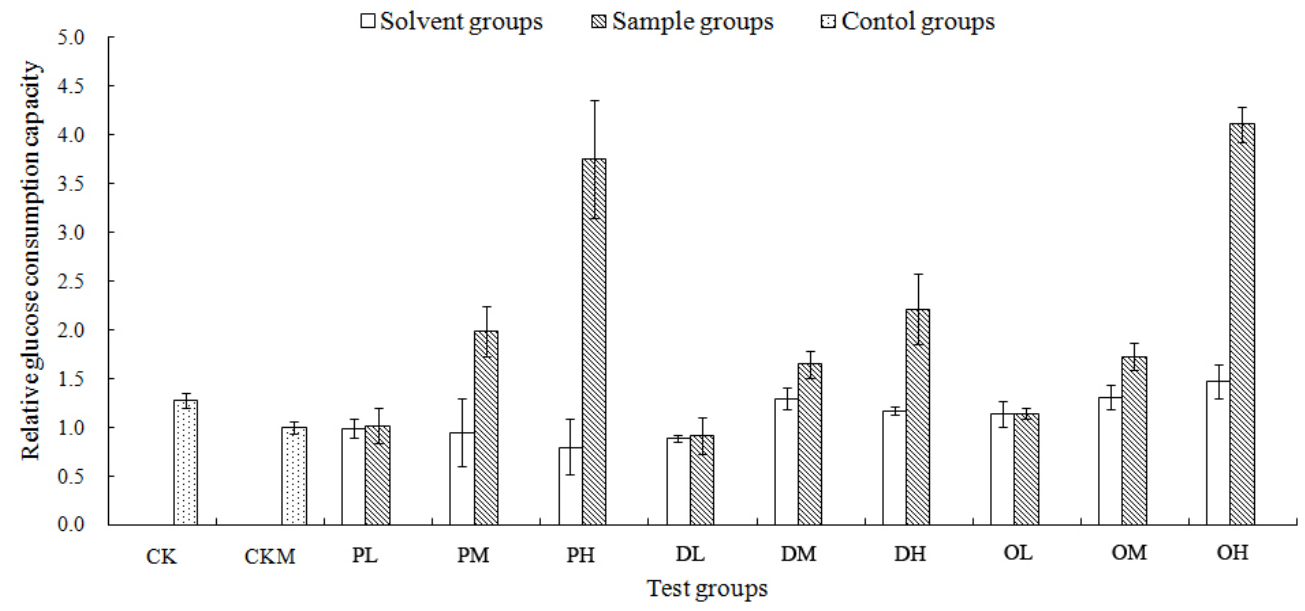

Figure 3. Relative glucose consumption capacity of HepG2 cells of treated groups

Table 3. Comparison of relative cells proliferation rate of HepG2 cells between treated groups

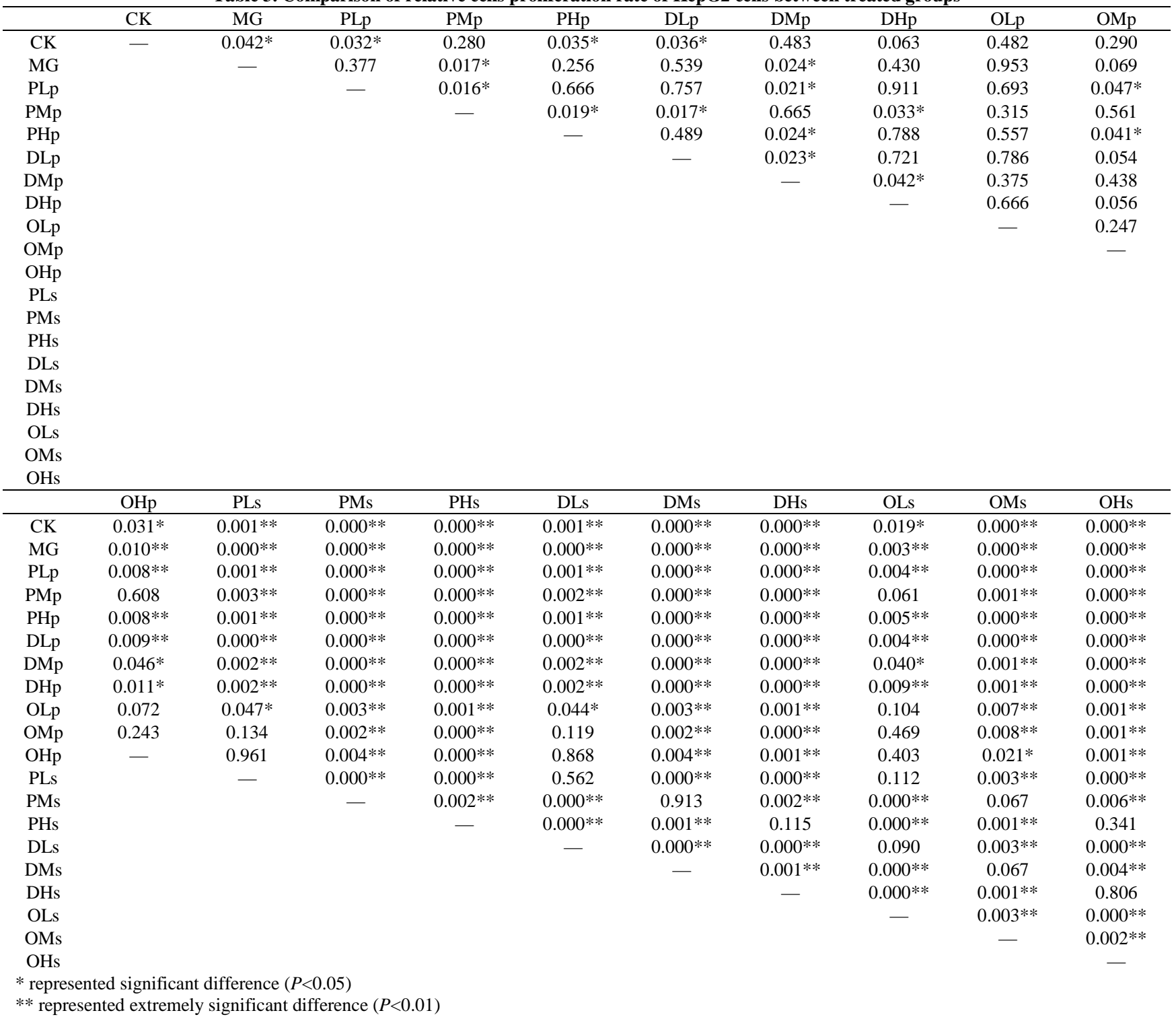


Table 3 shows the $P$ values between different groups. After the insulin treatment at high concentrations, an extremely significant difference $(P<0.01)$ in terms of the relative glucose consumption capacity of the $\mathrm{CK}$ group was observed compared with the MG group. It indicated that IR condition emerged and MG group was a successful model. Moreover, no extremely significant difference $(P<$ 0.01) was observed when the relative glucose consumption capacity of all solvent groups was compared with that of the MG group. However, when the relative glucose consumption capacity of DMSO groups (DLp, DMp, DHp) and olive oil groups (DMp, DHp) was compared with that of the MG group, the differences all reached a significant level $(P<0.05)$. In addition, when the relative glucose consumption capacity of all sample groups at the middle $(150 \mu \mathrm{g} / \mathrm{mL})$ and high $(300 \mu \mathrm{g} / \mathrm{mL})$ concentrations was compared with that of the $\mathrm{MG}$ group, the differences reached an extremely significant level $(P<$ 0.01). Besides, the highest difference in terms of the relative glucose consumption capacity was detected between OHs and MG groups. Furthermore, the pairwise comparisons between sample groups revealed that the relative glucose consumption capacity was in a concentration-dependent manner. Extremely significant differences $(P<0.01)$ in terms of the relative glucose consumption capacity were detected between all sample groups at the high concentration $(300 \mu \mathrm{g} / \mathrm{mL})$ and solvent groups.

\subsection{Correlation Analysis}

Figure 4 shows that the cell proliferation was negatively correlated with the IR level (Kendall's tau rank: $r=-0.851$, $\mathrm{n}=27, \mathrm{p}=0.000)$. A negative correlation was found between (olive oil + propolis) groups and the cell proliferation (Kendall's tau rank: $r=-0.998, n=9, p=0.04$ ). Moreover, a positive correlation was found between (DMSO+propolis) groups and the IR level (Kendall's tau rank: $r=1.000, n=9, p=0.004$ ). However, all other groups did not have any correlation with the cell proliferation or IR level. These results indicated that propolis exerted distinct effects on the cell proliferation and IR level, and the selection of a proper solvent played a crucial role.

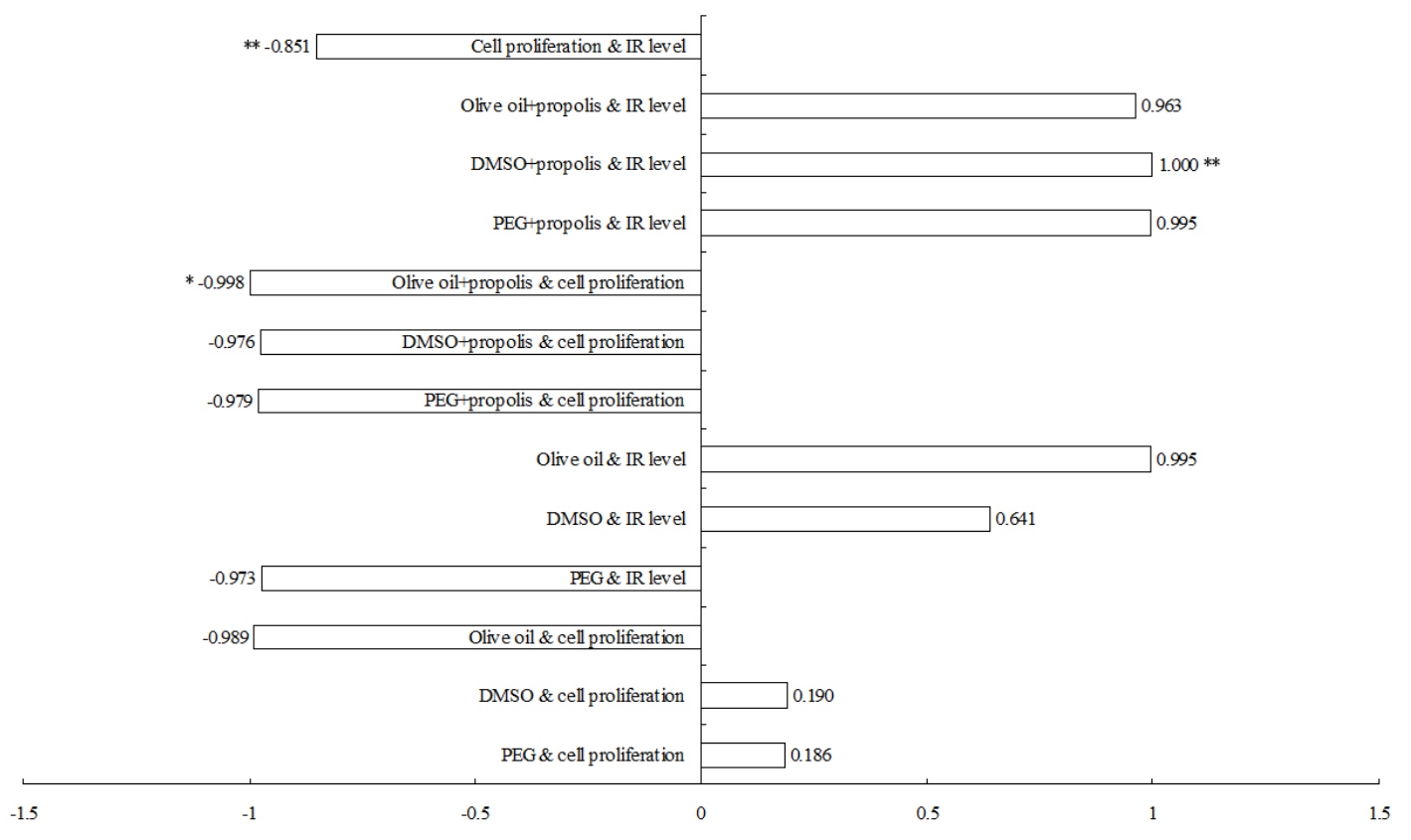

Figure 4. Correlation analysis of treated groups and the 2 indictors ( * represented significant difference $(P<0.05)$, ** represented extremely significant difference $(P<0.01)$.)

\section{Discussion}

As a nutritious food, propolis consists of abundant bioactive components, such as flavonoids, terpenes and phenolic acids. It plays a beneficial role in protecting liver from various pathological changes. However, its underlying internal mechanism still remains unclear. Recently, food safety and quality issues have become globally prominent. Therefore, a great deal of attention has been attracted on the safety of propolis consumption. The raw propolis used in this study was collected from North China, of which the main botanical source is well known as poplar (Populus sp.) [18]. The EEP of our samples contained many flavonoids, such as rutin, quercetin, kaempferol, apigenin, pinocembrin, chrysin and galangin. Although different in chemical constituents or plant sources, the biological activities of many propolis used in other studies are always similar [19,20,21]. In the present study, we showed that almost all sample groups exhibited an inhibited proliferation of HepG2 cells and a reduced IR level in vitro, and these effects were in a propolis concentration-dependent manner, which was consistent with other studies. Artepillin $C$ is one of the principal phenolic acids specifically found in Brazilian propolis, and it is highly cytotoxic to a variety of malignant human and murine tumor cell lines in vitro [22]. Furthermore, same results have been identified in tumortransplanted athymic and thymic mice [23]. Brazilian propolis was used to treat 10-week-old Otsuka LongEvans Tokushima Fatty (OLETF) rats, and the results suggested that propolis is an effective and functional food to prevent the IR development [24]. The hypolipidemic 
effect of Brazilian propolis has also been examined in a mouse model of diet-induced obesity, and data showed that propolis can significantly reduce levels of serum glucose and tends to mitigate the IR level [25]. The propolis samples used in previous studies were mostly collected from Brazil, and their effects on inhibiting cell proliferation and relieving IR have been systemically and exhaustively investigated. Until now, only few studies about Chinese propolis have been reported in these aspects. In our previous study, we have shown that different from Brazilian propolis, Chinese propolis consists of flavonoids, trepenes, esters, alcohols and so on [26]. Therefore, there must be some biological differences between Chinese propolis and Brazilian propolis. Although propolis from different geographic origins may possess different chemical compositions, they should have similar biological activities [27]. Our study provided the theoretical basis for the future medical research on propolis. Nevertheless, since we used only in vitro cultured cells as our experimental materials, it is necessary to confirm these findings through further verifications on animal experiments and clinical applications.

As solvents for propolis, their dissolution with propolis and oral safety should be concerned. Búfalo et al. reported that $70 \%$ ethyl alcohol has no effect either on cell morphology or on cell viability [28]. Sonmez et al. showed that $10 \%$ raw Turkish propolis and Sigma propolis (dissolved in $70 \%$ ethyl alcohol and propylene glycol) can inhibit the periodontopathogen microorganisms to some extent. Although not as effective as Australian and USA propolis, these propolis samples are safe for gingival fibroblasts. Moreover, synergism between propolis and anti-bacterial agents has been also observed [29]. In this regard, Noori et al. found that there is synergism between propolis and anti-microbial drugs against S. aureus, and its underlying mechanism is the interference with bacterial protein synthesis by those agents [30]. Therefore, we assumed that right solvent could improve the function of propolis. In the present study, only olive oil was found to have a significant effect on cell proliferation and IR of HepG2 cells among three types of solvents, and propolis could be easily dissolved in oils. Based on these findings, olive oil was a suitable auxiliary solvent of propolis. Moreover, tocopherols and phenolic compounds of virgin olive oil have a strong antioxidant activity and free radical-scavenging properties, resulting in an improved biological function of propolis. However, the main vegetal sources of propolis are Salix babylonica L., Quercus palustris Muncch. and Alnus japonica (Thunb.) Steud. in China [31]. More work is needed in future studies in order to clarify the influence of plant source on the biological function of propolis.

\section{Conclusion}

The raw propolis used in this study was collected from North China, its ethanol extract contained many flavonoids, such as rutin, quercetin, kaempferol, apigenin, pinocembrin, chrysin and galangin. Almost all EEP samples applied on HepG2 cells exhibited an inhibited proliferation of HepG2 cells and a reduced IR level in vitro, and these effects were in a propolis concentrationdependent manner. Moreover, only olive oil was found to have a significant effect on cell proliferation and IR of HepG2 cells among three types of solvents, and propolis could be easily dissolved in oils. So olive oil was a suitable auxiliary solvent of propolis. Nevertheless, since we used only in vitro cultured cells as our experimental materials, it is necessary to confirm these findings through further verifications on animal experiments and clinical applications.

\section{Acknowledgements}

We are grateful that this work was financially supported by the Building of Modern Agricultural Industry (Bees) R\&D Systems in China (NYCYTI-43-KXJ17).

\section{References}

[1] El-Serag, H.B., Marrero, J.A., Rudolph, L. and Reddy, K.R, "Diagnosis and treatment of hepatocellular carcinoma," Gastroenterology, 134(6), 1752-1763. May 2008.

[2] Bruix, J., and Sherman, M, "Management of hepatocellular carcinoma: an update," Hepatology, 53(3), 1020-1022. Mar. 2011.

[3] Baiz, D., Pozzato, G., Dapas, B., Farra, R., Scaggiante, B., Grassi, M. and Grassi, G, "Bortezomib arrests the proliferation of hepatocellular carcinoma cells HepG2 and JHH6 by differentially affecting E2F1, p21 and p27 levels," Biochimie, 91(3), 373-382. Mar. 2009.

[4] Absood, A., Hu, B., Bassily, N., and Colletti, L, "VIP inhibits human HepG2 cell proliferation in vitro," Regulatory Peptides, 146(1), 285-292. Feb. 2008.

[5] Fernández-Real, J.M., and Pickup, J.C, "Innate immunity, insulin resistance and type 2 diabetes," Trends in Endocrinology \& Metabolism, 19(1), 10-16. Jan. 2008.

[6] Haffner, S.M., Valdez, R.A., Hazuda, H.P., Mitchell, B.D., Morales, P.A., and Stern, M.P, "Prospective analysis of the insulin-resistance syndrome (syndrome X)," Diabetes, 41(6), 715722. Jun. 1992.

[7] Zhang, W.Y., Lee, J.J., Kim, I.S., Kim, Y., Park, J.S., and Myung, C.S, "7-O-Methylaromadendrin stimulates glucose uptake and improves insulin resistance in vitro," Biological and Pharmaceutical Bulletin, 33(9), 1494-1499. Sep. 2010.

[8] Zhang, W.Y., Lee, J.J., Kim, Y., Kim, I.S., Han, J.H., Lee, S.G. and Myung, C.S, "Effect of eriodictyol on glucose uptake and insulin resistance in vitro," Journal of agricultural and food chemistry, 60(31), 7652-7658. Jul. 2012.

[9] El-Sayed, E.S., Abo-Salem, O.M., Aly, H.A. and Mansour, A.M, "Potential antidiabetic and hypolipidemic effects of propolis extract in streptozotocin-induced diabetic rats," Pakistan Journal of Pharmaceutical Sciences, 22, 168-174. 2009.

[10] Kang, L.J., Lee, H.B., Bae, H.J. and Lee, S.G, "Antidiabetic effect of propolis: reduction of expression of glucose-6-phosphatase through inhibition of Y279 and Y216 autophosphorylation of GSK - 3 $\alpha / \beta$ in HepG2 cells," Phytotherapy research, 24(10), 15541561. Oct. 2010.

[11] Moț, A.C., Soponar, F. and Sârbu, C, "Multivariate analysis of reflectance spectra from propolis: Geographical variation in Romanian samples," Talanta, 81(3), 1010-1015. May 2010.

[12] Simone-Finstrom, M., and Spivak, M, "Propolis and bee health: the natural history and significance of resin use by honey bees," Apidologie, 41(3), 295-311. May 2007.

[13] Sipos, P., Gyõry, H., Hagymási, K., Ondrejka, P. and Blázovics, A, "Special wound healing methods used in ancient Egypt and the mythological background," World Journal of Surgery, 28(2), 211216. Feb. 2004.

[14] Burdock, G.A, "Review of the biological properties and toxicity of bee propolis (propolis)," Food Chemical Toxicology, 36(4), 347363. Apr. 1998.

[15] Bankova, V.S., de Castro, S.L. and Marcucci, M.C, "Propolis: recent advances in chemistry and plant origin," Apidologie, 31(1), 3-16. Jan.-Feb. 2000.

[16] Szliszka, E., Zydowicz, G., Janoszka, B., Dobosz, C., KowalczykZiomek, G. and Krol, W, "Ethanolic extract of Brazilian green 
propolis sensitizes prostate cancer cells to TRAIL-induced apoptosis," International Journal of Oncology, 38(4), 941-953. Apr. 2011.

[17] Mouse, H.A., Tilaoui, M., Jaafari, A., M'barek, L.A., Aboufatima, R., Chait, A. and Zyad, A, "Evaluation of the in vitro and in vivo anticancer properties of Moroccan propolis extracts," Revista Brasileira de Farmacognosia, 22(3), 558-567. May-Jun. 2012.

[18] Bankova, V, "Chemical diversity of propolis and the problem of standardization," Journal of Ethnopharmacology, 100(1), 114-117. Aug. 2005.

[19] Kujumgiev, A., Tsvetkova, I., Serkedjieva, Y., Bankova, V., Christov, R. and Popov, S, "Antibacterial, antifungal and antivira activity of propolis of different geographic origin," Journal of Ethnopharmacology, 64(3), 235-240. Mar. 1999.

[20] Uzel, A., Sorkun, K., Önçağ, Ö., Çoğulu, D. and Gençay, Ö, "Chemical compositions and antimicrobial activities of four different Anatolian propolis samples," Microbiological Research, 160(2), 189-195. Apr. 2005.

[21] Ahn, M.R., Kumazawa, S., Usui, Y., Nakamura, J., Matsuka, M. Zhu, F. and Nakayama, T, "Antioxidant activity and constituents of propolis collected in various areas of China," Food Chemistry, 101(4), 1383-1392. 2007.

[22] Ahn, M.R., Kunimasa, K., Kumazawa, S., Nakayama, T., Kaji, K., Uto, Y. and Ohta, T, "Correlation between antiangiogenic activity and antioxidant activity of various components from propolis," Molecular Nutrition \& Food Research, 53(5), 643-651. May 2009.

[23] Kimoto, T., Arai, S., Kohguchi, M., Aga, M., Nomura, Y., Micallef, M.J. and Mito, K, "Apoptosis and suppression of tumor growth by artepillin $\mathrm{C}$ extracted from Brazilian propolis," Cancer detection and prevention, 22(6), 506-515. 1998.

[24] Zamami, Y., Takatori, S., Koyama, T., Goda, M., Iwatani, Y. and Kawasaki, H, "Effect of propolis on insulin resistance in fructose- drinking rats," Yakugaku zasshi: Journal of the Pharmaceutical Society of Japan, 127(12), 2065-2073. 2007.

[25] Koya-Miyata, S., Arai, N., Mizote, A., Taniguchi, Y., Ushio, S., Iwaki, K. and Fukuda, S, "Propolis prevents diet-induced hyperlipidemia and mitigates weight gain in diet-induced obesity in mice," Biological and Pharmaceutical Bulletin, 32(12), 20222028. Dec. 2009.

[26] Tian, W.L., Zhao, Y.Z., Fang, X.M., Gao, L.Y. and Peng, W.J, "Analysis of volatile components in ethanolic extract of propolis," Modern Food Science and Technology, 28, 456-461, 475. Apr. 2012.

[27] Popova, M.P., Bankova, V.S., Bogdanov, S., Tsvetkova, I., Naydenski, C., Marcazzan, G.L. and Sabatini, A.G, "Chemical characteristics of poplar type propolis of different geographic origin," Apidologie, 38(3), 306-311. May 2007.

[28] Bufalo, M.C., Candeias, J.M. and Sforcin, J.M, "In vitro cytotoxic effect of Brazilian green propolis on human laryngeal epidermoid carcinoma (HEp-2) cells," Evidence-Based Complementary and Alternative Medicine, 6(4), 483-487. 2009.

[29] Sonmez, S., Kirilmaz, L., Yucesoy, M., Yücel, B. and Yilmaz, B, "The effect of bee propolis on oral pathogens and human gingival fibroblasts," Journal of Ethnopharmacology, 102(3), 371-376. Dec. 2005

[30] Noori, A.L., Al-Ghamdi, A., Ansari, M.J., Al-Attal, Y. and Salom, $\mathrm{K}$, "Synergistic effects of honey and propolis toward drug multiresistant Staphylococcus aureus, Escherichia coli and Candida albicans isolates in single and polymicrobial cultures," International Journal of Medical Sciences, 9(9), 793-800. Oct. 2012.

[31] Chen, S.L, The Apicultural Science in China, China Agriculture Press, Beijing, 2001, 666. 